\title{
Correction to: Implementation and Assessment Methodologies of Teachers' Training Courses for STEM Activities
}

\section{Scaradozzi $i^{1,2} \cdot$ L. Screpanti $^{1} \cdot$ L. Cesaretti ${ }^{1,3} \cdot$ M. Storti ${ }^{3} \cdot$ E. Mazzieri ${ }^{3}$}

Published online: 2 May 2019

(c) The Author(s) 2019

\section{Correction to: Tech Know Learn} https://doi.org/10.1007/s10758-018-9356-1

The article listed above was initially published with incorrect copyright information.

Upon publication of this Correction, the copyright of this article has been changed to "The Author(s)".

The original article has been corrected.

Publisher's Note Springer Nature remains neutral with regard to jurisdictional claims in published maps and institutional affiliations.

The original article can be found online at https://doi.org/10.1007/s10758-018-9356-1.

\section{Scaradozzi}

d.scaradozzi@staff.univpm.it

1 Dipartimento di Ingegneria dell'Informazione (DII), Università Politecnica delle Marche, Ancona, Italy

2 LSIS - umr CNRS 6168, Laboratoire des Sciences de l'Information et des Systèmes, Equipe I\&M (ESIL), Marseille, France

3 TALENT srl, Osimo, Ancona, Italy 